\title{
Proteasome inhibitor MG132 suppresses number and function of endothelial progenitor cells: Involvement of nitric oxide synthase inhibition
}

\author{
XIAO-SHENG HU, CHANG-QING DU, LIN YANG, XUE-YAN YAO and SHEN-JIANG HU \\ Institute of Cardiology, the First Affiliated Hospital, School of Medicine, \\ Zhejiang University, 310003 Hangzhou, P.R.China
}

Received October 22, 2009; Accepted November 25, 2009

DOI: 10.3892/ijmm_00000356

\begin{abstract}
The aim of this study was to determine whether proteasome inhibitor MG132 treatment has any effect on endothelial progenitor cells (EPCs). Total mononuclear cells (MNCs) were isolated from peripheral blood by Ficoll density gradient centrifugation. EPCs were identified as adherent cells double positive for DiLDL-up-take and lectin binding by direct fluorescent demonstrated under a laser scanning confocal microscope. After 7 days in culture, EPCs were stimulated with proteasome inhibitor MG132 in series of final concentrations of 20,50,100, $200 \mathrm{nmol} / 1$ for $12,24,48 \mathrm{~h}$. Cell proliferation and apoptosis were determined, respectively, by 3-(4,5-dimethylthiazol-2-yl)-2,5-diphenyltetrazolium bromide (MTT) assay, annexin V/propidium iodide binding assay. Colony-forming capacity was performed by colony assay. EPCs adhesion and migration were assayed with adhesion assay and transwell migration assay, respectively. The expression of endothelial nitric oxide synthase (eNOS) was assayed by Western blot analysis, while nitric oxide (NO) generation was detected using the Griess method. It was found that proteasome inhibitor MG132 decreased the number of EPCs and EPC colonies, increased EPC apoptosis, decreased EPC proliferative, adhesive, migration capacity and eNOS/ NO production in a concentration- and time-dependent manner. These data indicate that proteasome inhibitor MG132 suppresses the number and function of EPCs, and these actions may involve decreased eNOS/NO production in the EPCs.
\end{abstract}

\section{Introduction}

Endothelial progenitor cells (EPCs) are the precursors of mature endothelial cells. They possess the capacity to migrate,

Correspondence to: Dr Sheng-Jiang Hu, Institute of Cardiology, the First Affiliated Hospital, School of Medicine, Zhejiang University, 310003 Hangzhou, P.R. China

E-mail: s0hu0001@hotmail.com

Key words: proteasome inhibitor, endothelial progenitor cells, cell number and function, endothelial nitric oxide synthase/nitric oxide proliferate and differentiate into endothelial lineage cells (1). It is well known that circulating endothelial progenitor cells contribute to postnatal neovascularization and re-endothelialization $(2,3)$. Moreover, many studies suggest that the number of EPCs serves as a biological marker for vascular function (4). It is also a better predictor for future cardiovascular events $(5,6)$.

There is increasing evidence that endothelial nitric oxide synthase/nitric oxide (eNOS/NO) plays significant roles in regulating the number and function of stem/progenitor cells (7-10). These studies showed that eNOS contributes to the effect of VEGF in the improvement of EPC proliferation, mobilization and serves as a significant regulator of angiogenesis (7-9). As a significant regulator of neovascularization, NO can enhance EPC function via activating the PI3K/Akt signal pathway (10).

The ubiquitin-proteasome system is the major pathway of nonlysosomal degradation of intracellular proteins in eukaryotic cells (11). In addition to the degradation of damaged and unnecessary proteins, this pathway plays key roles in a variety of important intracellular events, including inflammatory processes, cell proliferation, apoptosis, and gene expression. Proteasome is the central element of this pathway. In vitro and in vivo, proteasome inhibitors possess anti-inflammatory, antiproliferative and proapoptotic features $(12,13)$. It has been suggested that inhibition of the proteasome to a defined degree may offer a promising tool for treating various diseases (14). Particularly, it was shown that lowdose proteasome inhibitiors (between 20 and $200 \mathrm{nmol} / \mathrm{l}$ ) upregulated the expression and activity of eNOS, induced basal NO production and downregulated the expression of the vasoconstrictor endothelin-1 (ET-1) in primary endothelial cells $(15,16)$, indicating that the partial proteasome inhibition may promote eNOS-dependent vascular protection.

It has been noted that one identical dose of proteasome inhibitor has distinct effects on different cell types (14). Proteasome inhibition induces apoptosis in rapidly proliferating cells while protects from apoptosis in differentiated and quiescent cells $(17,18)$. On the basis of the above considerations, it was of interest to see what effects proteasome inhibitor MG132 has, in the dosage between 20 and 200 $\mathrm{nmol} / \mathrm{l}$ which is considered as low dosage in the endothelial cells $(15,16)$, on the number and function of EPCs, and whether the eNOS/NO pathway is involved in the effects of 
MG132 on EPCs biology. Therefore, in this study, we investigated the effects of MG132 in the dosage between 20 and $200 \mathrm{nmol} / \mathrm{l}$ on proliferation, apoptosis, migration, adhesion, eNOS protein expression and NO production in cultured human peripheral blood EPCs.

\section{Materials and methods}

Isolation and cultivation of EPC. Human EPC were obtained from healthy adults and cultured according to previously described techniques $(4,19)$. Written informed consent was obtained from all people involved in the study. The volunteers had no risk factors of CAD including hypertension, diabetes, smoking, positive family history of premature CAD and hypercholesterolemia, and were all free of wounds, ulcers, retinopathy, recent surgery, inflammatory, malignant diseases or medications that may influence EPC kinetics. Briefly, total mononuclear cells (MNC) were isolated from the peripheral venous blood of study subjects by Ficoll density gradient centrifugation. Cells were plated on culture dishes coated with human fibronectin (Chemicon) and maintained in Medium 199 (Sigma) supplemented with $20 \%$ fetal calf serum, penicillin $(100 \mu / \mathrm{ml})$, streptomycin $(100 \mu \mathrm{g} / \mathrm{ml})$ and vascular endothelial growth factor (VEGF, $50 \mathrm{ng} / \mathrm{ml}$ ).

After 4 days of culture, nonadherent cells were removed by washing with phosphate-buffered saline (PBS), and adherent cells were cultured continually by the addition of new media for another 3 days. Proteasome inhibitor MG132 (carbobenzoxyl-Lleucyl-L-leucyl-L-leucinal; Sigma) was dissolved in dimethyl sulfoxide (DMSO), and attached cells were treated with series of final concentrations of $20,50,100$, $200 \mathrm{nmol} / \mathrm{l}$ for $12,24,48 \mathrm{~h}$, respectively. These concentrations were known to inhibit partial proteasome in endothelial cells $(15,16)$. The final concentration of DMSO in culture medium was $0.1 \%$ and control cells were treated with the culture medium containing an amount of dimethyl sulfoxide (DMSO) equivalent to that used in the MG132 solutions.

Cell staining. Fluorescent chemical detection of EPCs was performed on attached MNCs after 7 days in culture. Direct fluorescent staining was used to detect dual binding of FITClabelled Ulex europaeus agglutinin (UEA-1; Sigma) and 1,1-dioctadecyl-3,3,3,3-tetramethylindocarbocyanine (DiI)labelled acetylated low-density lipoprotein (acLDL; Molecular Probe) at day 7. Cells were first incubated with acLDL (10 $\mu \mathrm{g} /$ $\mathrm{ml}$ ) at $37^{\circ} \mathrm{C}$ for $4 \mathrm{~h}$ and then fixed with $2 \%$ paraformaldehyde for $10 \mathrm{~min}$. After washing, cells were reacted with UEA-1 $(10 \mu \mathrm{g} / \mathrm{ml})$ for $1 \mathrm{~h}$. After staining, samples were viewed using an inverted fluorescence microscope (Leica Microsystems AG, Wetzlar, Germany) and were further demonstrated by laser scanning confocal microscopy (LSCM, Leica). Cells displaying double positive fluorescence were identified as differentiating EPCs $(5,19)$. Two or three independent investigators evaluated the number of EPCs per well by counting 15 randomly selected high-power fields (x200).

Colony assay. After 7 days of culture, human EPCs were gently detached with $0.25 \%$ trypsin. Cells $\left(1 \times 10^{5}\right)$ were seeded in methylcellulose plates (Methocult GF H4434, Cell Systems) with $100 \mathrm{ng} / \mathrm{ml}$ human recombinant VEGF in the presence or absence of MG132. Plates were studied under phase contrast microscopy, and colonies were counted after 2 days of incubation by two independent investigators $(20,21)$.

EPC proliferation assay. The effect of proteasome inhibitor MG132 on EPC proliferation was determined by the MTT assay. After being cultured for 7 days, EPCs were digested with $0.25 \%$ trypsin and then were cultured in 96-well plates (104 cells per well) in M199 medium containing $10 \%$ fetal bovine serum in the absence or presence of different concentrations of proteasome inhibitor MG132. After incubation for 12, 24, $48 \mathrm{~h}$, EPCs were incubated with $10 \mathrm{ml}$ MTT (5 g/l) for another $4 \mathrm{~h}$ at $37^{\circ} \mathrm{C}$. Then the supernatant was removed and $150 \mathrm{ml}$ dimethyl sulfoxide (DMSO) was added to each well. The culture plate was shaken for $10 \mathrm{~min}$. The optical density (OD) value was read at $490 \mathrm{~nm}$ (19).

EPC apoptosis assay. To identify EPC apoptosis, the apoptotic rate of EPCs was detected by the Annexin V-FITC Apoptosis detection kit (BioVision) according to the manufacturer's protocol. Briefly, after incubation with MG132 of different concentrations for $48 \mathrm{~h}$, both floating and attached cells were harvested and washed twice with PBS. Isolated EPCs $\left(5 \times 10^{6}\right)$ were resuspended in $500 \mu 1$ binding buffer. FITC-annexin V (5 $\mu \mathrm{l})$ and propidium iodide (PI, $5 \mu \mathrm{l})$ working solution were added and then cells were incubated at room temperature for $5 \mathrm{~min}$ in the dark. After the incubation period, cells were analyzed by flow cytometry (FACS Calibur, USA), the annexin V-FITC binding was analyzed by FITC signal detector (FL1) and PI staining by phycoerythrin emission signal detector (FL3). Apoptotic cells were identified as annexin V $(+)$ and PI (-).

Cell adhesion assay. EPCs were washed with PBS and detached with $0.25 \%$ trypsin. After centrifugation and resuspension in M199 with 5\% FBS, identical cell numbers were replated onto fibronectin-coated culture dishes and were incubated for $30 \mathrm{~min}$ at $37^{\circ} \mathrm{C}$. Adherent cells were counted in a blinded manner by independent investigators (19).

Migration assay. EPC migration was evaluated by using a transwell migration assay. In brief, after being preincubated without or with different concentrations of MG132, isolated EPCs were detached using $0.25 \%$ trypsin, harvested by centrifugation, resuspended in $500 \mu 1 \mathrm{M} 199$ and were counted; then $3 \times 10^{5}$ EPCs in $1500 \mu 1$ culture medium were placed in the upper chamber of 8.0-mm pore size transwell. M199 $(2000 \mu \mathrm{l})$ and human recombinant $\operatorname{VEGF}(50 \mathrm{ng} / \mathrm{ml})$ were placed in the lower compartment. After a 24-h incubation at $37^{\circ} \mathrm{C}$, the cells that had not migrated were removed from the upper surface of the filters using cotton swabs and those that migrated to the lower surface of the filters were fixed in $4 \%$ paraformaldehyde for $10 \mathrm{~min}$ and stained with $2 \%$ methylrosanilinium chloride for $10 \mathrm{~min}$. Migration was determined by counting the cell number at $\mathrm{x} 200$ magnification. Five visual fields were chosen randomly for each assay. The average number of the migrating cells in 5 fields was taken as the cell migration number of the group. Six independent experiments were examined, and the groups represent the mean of the 6 separate experiments. 

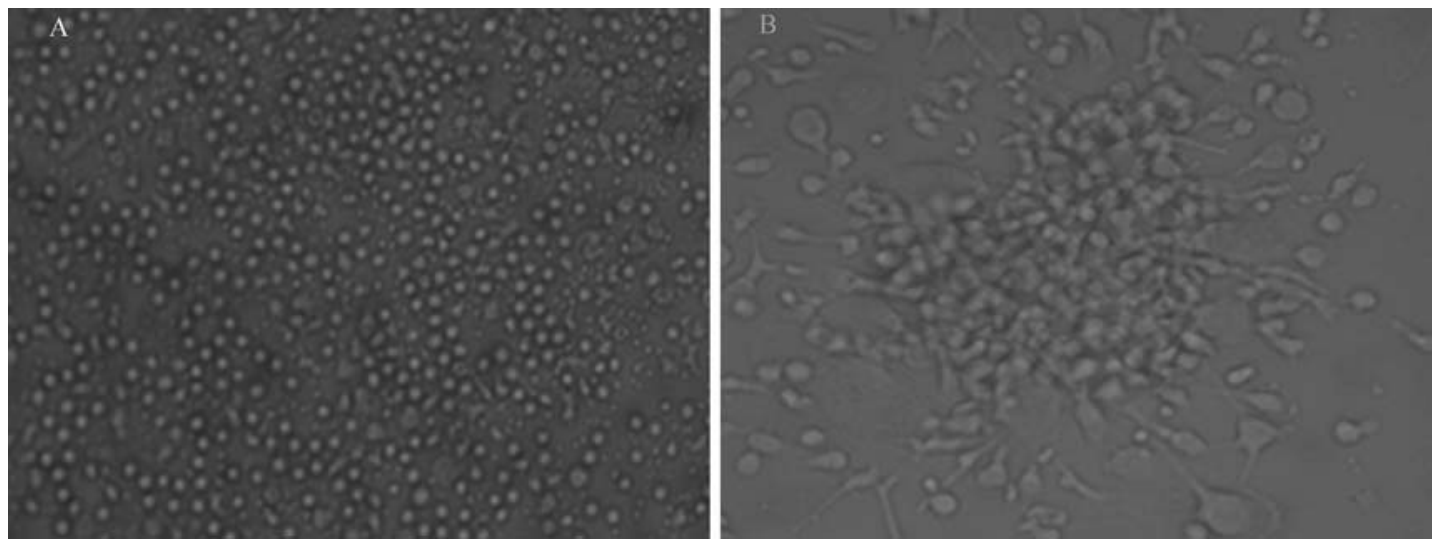

Figure 1. (A) Mononuclear cells were plated on culture dishes coated with human fibronectin just after isolated from peripheral blood (x200). (B) After 7 days in culture, attached cells exhibited a typical clony-forming unit (CFU-EPC), with a characteristic core of round cells and sprouting spindle cells at the periphery $(\mathrm{x} 200)$.

Determination of NO generation. The level of nitrite/nitrate in the conditioned medium of EPCs was measured as described previously (22). A nitrite detection kit (Beyotime Biotech Inc., Jiangsu, P.R. China) was used according to the manufacturer's instructions. Briefly, $50 \mu \mathrm{l}$ of medium or standard $\mathrm{NaNO}_{2}$ was mixed with $50 \mu \mathrm{l}$ of Griess reagent in a 96-well plate. After $15 \mathrm{~min}$, optical density was read in a microplate reader at $540 \mathrm{~nm}$ with a spectrophotometer. Each experiment was performed in triplicate. A standard curve using $\mathrm{NaNO}_{2}$ was generated for each experiment for quantification. Results of three independent experiments were used for statistical analysis.

Western blot analysis. To assess eNOS expression, EPCs were washed 3 times with PBS and lysed with RIPA. Proteins (30 $\mu \mathrm{g}$ per lane) were denatured, loaded onto an $8.0 \%$ sodium dodecyl sulphate-polyacrylamide gel for electrophoresis (SDS-PAGE). The proteins were transferred to nitrocellulose membranes by electroblotting. Membranes were soaked in a blocking solution containing PBS with 5\% non-fat dried milk and $0.05 \%$ Tween-20 for $1 \mathrm{~h}$ at room temperature. The membranes were then incubated with antieNOS monoclonal antibodies (Santa Cruz Biotechnology, Santa Cruz, CA, USA) at a dilution of $1: 400$ at $4^{\circ} \mathrm{C}$ overnight. The membrane was then incubated with peroxidase labeled with secondary antibody (Santa Cruz Biotechnology) at a dilution of 1:1000 for $2 \mathrm{~h}$ at room temperature. Positive protein bands were visualized with an ECL kit (Amersham, USA). Western blot analysis with a mouse polyclonal antibody raised against glyceraldehyde-3-phosphate Dehydrogease (GAPDH) (Santa Cruz Biotechnology) was used as a protein loading control. The bands corresponding to eNOS were detected using the appropriate chemiluminescence reagent (Amersham Pharmacia Biotech, Piscataway, NJ, USA).

Statistical analysis. All statistical analyses were performed with SPSS15.0. Data were expressed as mean \pm SD from at least three independent experiments. One-way ANOVA and independent samples t-test were used to analyze the differences of variables. Probability values were considered significant at $\mathrm{P}<0.05$.

\section{Results}

Identification of EPCs. Total MNCs isolated and cultured for 7 days resulted in a spindle-shaped, EC-like morphology (Fig. 1). To identify whether EPCs were present in cultured peripheral blood mononuclear cells, double fluorescence labeling for DiI-acLDL and UEA-1 was performed in the adherent cells at day 7. It was observed under confocal microscope that the most cultured adherent cells were positive for both DiI-acLDL and UEA-1 (Fig. 2). The double positive cells were recognized as differentiating EPCs. Our group and other investigators have previously demonstrated that EPCs isolated in this fashion also exhibit many other endothelial characteristics, including expression of CD31, vWF and vascular endothelial growth factor receptor 2 (VEGFR-2) $(20,21)$.

Effect of MG132 on EPC numbers. Incubation of isolated human EPCs with MG132 for $48 \mathrm{~h}$ decreased the number of EPCs in a concentration-dependent manner, which became apparent at $50 \mathrm{nmol} / \mathrm{l}$, with a peak at $200 \mathrm{nmol} / \mathrm{l}$ (Table I). In time-course experiments performed with an MG132 concentration of $200 \mathrm{nmol} / 1$, decrease of EPC number became apparent at $12 \mathrm{~h}$ and reached the maximum at $48 \mathrm{~h}$ (Table II). The low concentration group ( $20 \mathrm{nmol} / \mathrm{l})$ showed no significant difference compared to the control group.

Effect of MG132 on proliferative capacity and clonal expansion in EPCs. Incubation of isolated human EPCs with MG132 decreased EPC proliferative capacity in a concentration- (Table I) and time-dependent (Table II) manner. The number of colonies was significantly lower in EPCs that had been pretreated with MG132, also in a concentrationdependent manner (Table I). The low concentration group (20 nmol/l) showed no significant difference compared to the control group.

Effect of MG132 on apoptosis in EPCs. Fig. 3 depicts the dose-dependent effect of MG132 on EPC apoptosis. Incubation of EPCs with MG132 induced EPC apoptosis in a concentration-dependent manner, with a maximal effect achieved at $200 \mathrm{nmol} / \mathrm{l}$. 

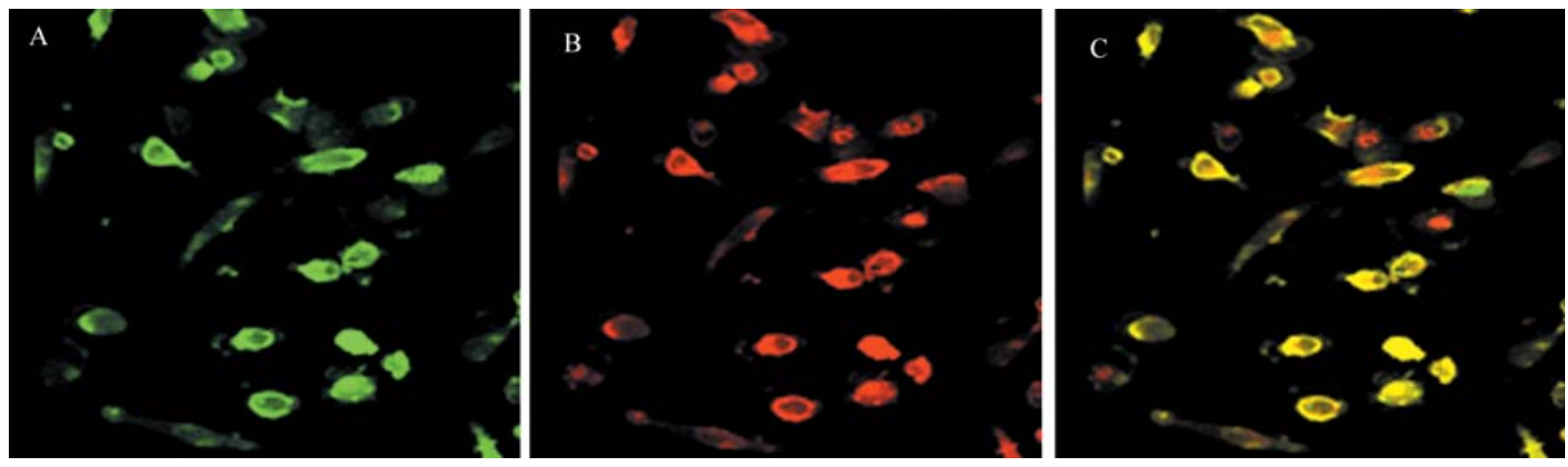

Figure 2. Identification of EPCs. Representative micrographs of UEA-1 positive cells (A, green), DiI-acLDL positive cells (B, red) and the double positive cells for DiI-acLDL and UEA-1 (C, yellow) are shown (x200).
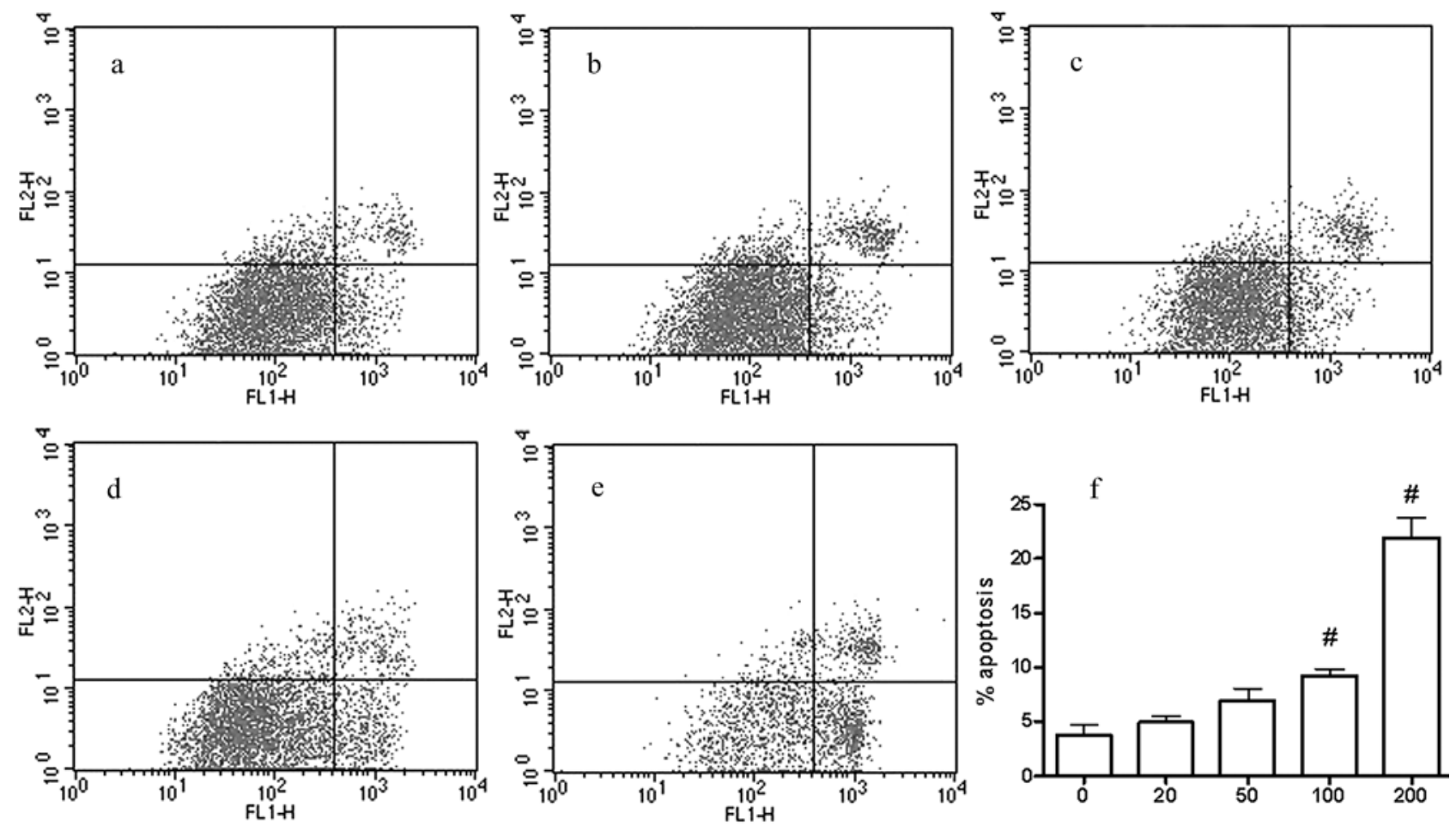

Figure 3. Effects of MG132 on the apoptosis of EPCs. Incubation of EPCs with MG132 in a series of final concentrations (0, 20, 50, 100, 200 nmol/1) for 48 h induced apoptosis in a concentration-dependent manner. Representative diagraphs altered by different concentrations of proteasome inhibitors are shown: (a) control, (b) treatment with $20 \mathrm{nmol} / 1$ of MG132, (c) treatment with $50 \mathrm{nmol} / 1$ of MG132, (d) treatment with $100 \mathrm{nmol} / 1$ of MG132, (e) treatment with $200 \mathrm{nmol} / 1$ of MG132, (f) representative bar chart showing percentage of apoptotic cells. Data shown are mean $\pm \mathrm{SD} ; \mathrm{n}=3$, compared to control group, ${ }^{*} \mathrm{P}<0.05 ;{ }^{*} \mathrm{P}<0.01$.

Effect of MG132 on the migratory capacity of EPCs. The effect of MG132 on EPC migration was analyzed in a transwell migration assay. MG132 profoundly impaired cell migration, in a concentration- (Table I) and time-dependent (Table II) manner.

Effect of MG132 on EPC adhesiveness. Incubation of isolated human EPCs with MG132 decreased EPCs adhesive capacity in a concentration- (Table I) and time-dependent (Table II) manner.

Effect of MG132 on NO generation in EPCs. As demonstrated in Fig. 4, treatment of EPCs with MG132 in a series of final concentration $(0,20,50,100,200 \mathrm{nmol} / \mathrm{l})$ for $48 \mathrm{~h}$ induced a decrease of NO generation in a concentration-dependent manner, which may influence the function of EPCs (10).

Effects of MG132 on eNOS protein expression in EPCs. Western blotting was performed to determine whether MG132 affected eNOS protein expression of EPCs. Western blot analysis showed that the expression of eNOS (the relative light density values of control group and different concentration of MG132) had decreased significantly in the cells treated with MG132 in a concentration-dependent manner (Fig. 5), suggesting that the inhibitory effect of MG132 may be mediated through decreasing eNOS protein expression. 
Table I. Effect of MG132 on EPC number, proliferation, migration, and adhesion capacity in a dose-course experiment $($ mean $\pm \mathrm{SD} ; \mathrm{n}=6){ }^{\mathrm{a}}$

\begin{tabular}{|c|c|c|c|c|c|}
\hline $\begin{array}{l}\text { Group } \\
\mathrm{nmol} / \mathrm{l}\end{array}$ & $\begin{array}{c}\text { Number } \\
(\text { EPC x200) }\end{array}$ & $\begin{array}{l}\text { Proliferation } \\
\text { (A490 nm) }\end{array}$ & $\begin{array}{c}\text { Adhesion } \\
\text { (adherent cells x200) }\end{array}$ & $\begin{array}{c}\text { Migration } \\
\text { (migratory cells x200) }\end{array}$ & $\begin{array}{l}\text { Colony formation } \\
\text { (colonies x200) }\end{array}$ \\
\hline Control & $49.2 \pm 5.1$ & $0.427 \pm 0.012$ & $31.7 \pm 4.8$ & $21.7 \pm 3.9$ & $24.9 \pm 1.3$ \\
\hline 20 & $47.3 \pm 2.5$ & $0.388 \pm 0.029$ & $29.8 \pm 3.0$ & $20.9 \pm 2.4$ & $24.2 \pm 0.8$ \\
\hline 50 & $43.7 \pm 3.1^{\mathrm{b}}$ & $0.360 \pm 0.035^{b}$ & $26.5 \pm 3.3^{b}$ & $17.9 \pm 2.9^{\mathrm{b}}$ & $22.7 \pm 1.1^{\mathrm{b}}$ \\
\hline 100 & $31.2 \pm 1.1^{\mathrm{c}}$ & $0.339 \pm 0.034^{c}$ & $16.8 \pm 2.8^{c}$ & $14.9 \pm 2.3^{\mathrm{c}}$ & $12.6 \pm 1.2^{\mathrm{c}}$ \\
\hline 200 & $21.5 \pm 4.2^{\mathrm{c}}$ & $0.290 \pm 0.005^{\mathrm{c}}$ & $12.6 \pm 2.3^{\mathrm{c}}$ & $8.0 \pm 2.1^{\mathrm{c}}$ & $8.8 \pm 1.0^{\mathrm{c}}$ \\
\hline
\end{tabular}

${ }^{\mathrm{a} C e l l s}$ were treated with MG132 in a series of final concentrations $(0,20,50,100,200 \mathrm{nmol} / \mathrm{l})$ for $48 \mathrm{~h}$. Compared to control group, ${ }^{\mathrm{b}} \mathrm{P}<0.05$; ${ }^{\mathrm{c}} \mathrm{P}<0.01$.

Table II. Effect of $200 \mathrm{nmol} / 1 \mathrm{MG} 132$ on EPC number, proliferation, migration, and adhesion capacity in a timecourse experiment $($ mean $\pm \mathrm{SD} ; \mathrm{n}=6){ }^{\mathrm{a}}$

\begin{tabular}{lrll}
\hline & & Control & \multicolumn{1}{c}{$\begin{array}{c}\text { MG132 } \\
\text { Mmol/1 }\end{array}$} \\
\hline Number & $0 \mathrm{~h}$ & $48.7 \pm 3.6$ & $47.1 \pm 2.7$ \\
(EPC x200) & $12 \mathrm{~h}$ & $49.6 \pm 3.1$ & $43.0 \pm 3.6^{\mathrm{b}}$ \\
& $24 \mathrm{~h}$ & $48.5 \pm 2.9$ & $32.3 \pm 3.0^{\mathrm{c}}$ \\
& $48 \mathrm{~h}$ & $49.2 \pm 5.1$ & $21.5 \pm 4.2^{\mathrm{c}}$ \\
Proliferation & $0 \mathrm{~h}$ & $0.430 \pm 0.017$ & $0.427 \pm 0.013$ \\
(A490 nm) & $12 \mathrm{~h}$ & $0.432 \pm 0.008$ & $0.390 \pm 0.022^{\mathrm{b}}$ \\
& $24 \mathrm{~h}$ & $0.429 \pm 0.004$ & $0.336 \pm 0.015^{\mathrm{c}}$ \\
& $48 \mathrm{~h}$ & $0.427 . \pm 0.012$ & $0.290 \pm 0.005^{\mathrm{c}}$ \\
Adhesion & $0 \mathrm{~h}$ & $34.0 \pm 2.5$ & $33.2 \pm 1.8$ \\
(adherent cells & $12 \mathrm{~h}$ & $34.4 \pm 3.9$ & $27.1 \pm 3.7^{\mathrm{b}}$ \\
x200) & $24 \mathrm{~h}$ & $33.3 \pm 4.7$ & $17.6 \pm 3.0^{\mathrm{c}}$ \\
& $48 \mathrm{~h}$ & $31.7 \pm 4.8$ & $12.6 \pm 2.3^{\mathrm{c}}$ \\
Migration & $0 \mathrm{~h}$ & $22.8 \pm 4.2$ & $19.4 \pm 3.2$ \\
(migratory cells & $12 \mathrm{~h}$ & $22.7 \pm 3.9$ & $17.6 \pm 2.7$ \\
x200) & $24 \mathrm{~h}$ & $21.8 \pm 3.9$ & $15.7 \pm 2.5^{\mathrm{b}}$ \\
& $48 \mathrm{~h}$ & $21.7 \pm 3.9$ & $8 \pm 2.1^{\mathrm{c}}$ \\
\hline
\end{tabular}

${ }^{\mathrm{a} C e l l s}$ were treated with $200 \mathrm{nmol} / \mathrm{l} \mathrm{MG132}$ for different time $(0,12$, 24, 48 h). Compared to control group, ${ }^{b} \mathrm{P}<0.05$; ${ }^{\mathrm{P}}<0.01$.

\section{Discussion}

The ubiquitin-proteasome system is the major proteolytic system for non-lysosomal degradation of cellular proteins involved in numerous cellular processes (11). Due to the considerable diversity of its degradated substrates, proteasome inhibition may become a valuable and promising strategy in treating various human diseases. At the same time, a growing number of experimental studies demonstrate that it is centrally involved in the physiological and pathophysiological processes of cardiovascular diseases such as atherosclerosis

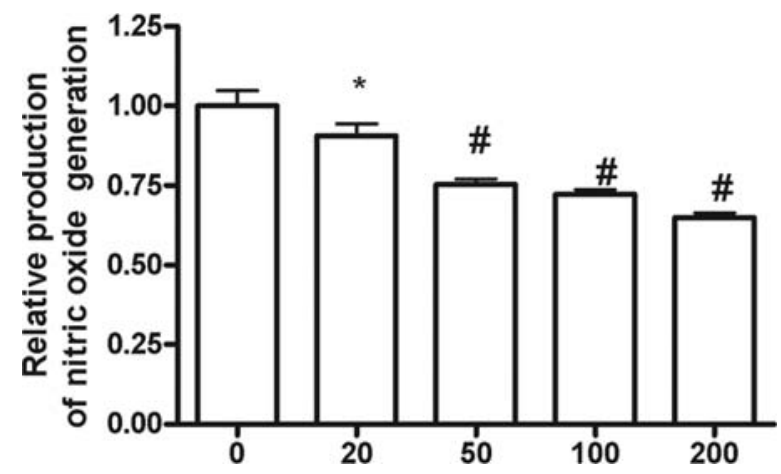

Figure 4. Effects of MG132 on nitric oxide (NO) generation in EPCs. The production of NO was assayed by the Griess method. Treatment of EPCs with MG132 in a series of final concentrations $(0,20,50,100,200 \mathrm{nmol} / \mathrm{l})$ for $48 \mathrm{~h}$ induced decreased NO generation. The data are shown as percentage of control group; $n=3$, compared to control group, ${ }^{*} \mathrm{P}<0.05$; ${ }^{\#} \mathrm{P}<0.01$.
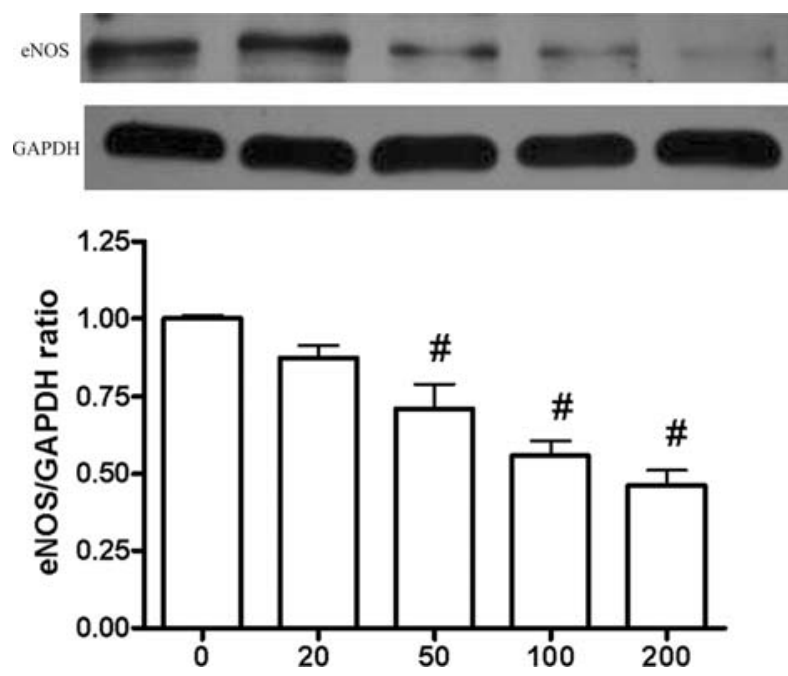

Figure 5. Effects of MG132 on endothelial nitric oxide synthase (eNOS) protein expression in EPCs. Western blot analysis of eNOS protein expression of EPCs by a variety of concentrations of MG132. The expression of eNOS was significantly decreased in the cells treated with MG132 in a concentration-dependent manner. A representative blot from three independent experiments is shown. The data are shown as percentage of control group; data are mean $\pm \mathrm{SD} ; \mathrm{n}=3$, compared to control group, ${ }^{*} \mathrm{P}<0.05 ;{ }^{\text {}} \mathrm{P}<0.01$. 
(23), heart failure (24), ischemia-reperfusion injuries (25), post-intervention restenosis (26) and cardiac hypertrophy (27).

The peptide aldehyde MG132, primarily inhibiting the chymotrypsin-like function of the $20 \mathrm{~S}$ proteasome, is comparably selective and is widely used in vitro experiments (28). Recent animal studies and clinical trials documented that the divergent effects of proteasome inhibitors depend on the cell type and on the dosage (14). Meiners et al demonstrated that local administration of high doses MG 132 for 5 min markedly reduced neointima formation in balloon injured carotid arteries, indicating that inhibition of proteasome activity is a new method in treatment of restenosis (26). Furthermore, they showed that low-dose proteasome inhibition did not affect cell viability, while upregulated expression of endothelial NO synthase (eNOS) and basal NO production in primary endothelial cells (15). In contrast, high doses induced endothelial cells to apoptosis, diminished expression of eNOS and NO production (16).

A biphasic dose effect of proteasome inhibitors was also observed by Veschini and his colleagues (29). They showed that bortezomib, another proteasome inhibitor which was approved by the FDA in 2003 for the therapy of relapsed and refractory multiple myeloma (30), exerted a double-edged effect on human umbilical vein cells (HUVECs): at low doses it allowed cell proliferation and angiogenesis, whereas at high doses, still achievable in vivo, it induced growth arrest and angiogenesis blockade. In line with the above observations, the beneficial effect of proteasome inhibitors in endothelial function has been shown by many other experiments, accompanied by enhanced expression of eNOS (15,16,31-33). Thus, it seems that partial proteasome inhibition appears to offer beneficial effects on endothelial function.

Since EPCs are the precursors of mature endothelial cells and play important roles in endothelium maintenance, it is of interest to see what effects proteasome inhibitor has on the number and function of EPCs. In the present study, we treated EPCs with proteasome inhibitor MG132 in a series of final concentrations of $20,50,100,200 \mathrm{nmol} / \mathrm{l}$. These concentrations are known to inhibit partial proteasome in endothelial cells, chymotrypsin-like activity of proteasome was reduced while its caspase- and trypsin-like activities were retained $(15,16)$. Our data showed that proteasome inhibitor MG132 in these dosages 1) decreased the number of EPC; 2) decreased the proliferative, migratory, adhesive, and in vitro colony forming capacity of EPC; 3 ) resulted in significant EPC apoptosis; and 4) decreased EPC production of eNOS/NO in a concentration- and time-dependent manner. Therefore, these results revealed that proteasome inhibitor MG132 suppresses number and function of endothelial progenitor cells and the eNOS/NO pathway may be involved in the effects of MG132 on EPC biology. Whether chymotrypsin-, caspase- and trypsinlike activities of proteasome in EPCs would change or not need further investigation. Based on the present results that MG132 exhibited inhibited effects on number and functions of EPCs, the three proteolytic activities would probably be suppressed in MG132-treated EPCs. Given the well established role of EPCs participating in neovascularization and reendothelialization, these findings demonstrate that MG132 of the dosage used in our studies can affect the EPC number and functions, which may lead to endothelial dysfunction and promote the progression of CAD.

To the best of our knowledge, the present study is the first to provide evidence of a role of the proteasome in the regulation of EPC biology. The mechanisms by which MG132 reduces the EPC number and activity remain to be determined. There are several possible explanations, one might be the increased apoptosis of endothelial progenitor cells. CD34-positive EPCs were shown to be very sensitive to apoptosis induction. Several apoptotic accelerators such as p53 and c-myc, antiapoptotic mediators such as bcl-2 and inhibitors of apoptosis are substrates of the proteasome (34-36). Moreover, MG132 is known to induce apoptotic cell death, especially in prolifelating cells $(17,18)$. Similar to rapidly proliferating tumor cells (37), EPCs may be more hypersensitive to the proteasome inhibitors than endothelial cells. In this study, we also found that treatment of EPCs with MG132 resulted in significant apoptosis by annexin V/ propidium iodide binding assay.

Secondly, MG132 may interfere with the signaling pathways regulating EPC biology. Many studies have demonstrated that endothelial nitric oxide synthase/nitric oxide (eNOS/NO) plays a significant role in regulating the number and function of stem/progenitor cells (7-10). Our data showed MG132 down-regulated eNOS protein expression, leading to a significant decrease in NO generation, which may promote EPC apoptosis and poor function.

Govers et al (38) reported that intracellular NO productions from bovine aortic endothelial cells were reduced by $20 \mu \mathrm{M}$ MG132 and lactacystin treatment, which is a huge difference (100-fold) in comparison to highest concentration of $0.2 \mu \mathrm{M}$ used in our study. Interestingly, they observed that neither MG132 nor lactacystin affected eNOS expression in bovine aortic endothelial cells even at this high concentration.

While in another study, Wei et al (39) used MG132 in an increased concentration of $10 \mu \mathrm{M}$ to treat bovine aortic endothelial cells and found a decreased eNOS serine 1179 phosphorylation in bovine aortic endothelial cells timedependently, whereas the levels of total eNOS were not significantly affected. The disagreement on eNOS protein expression between these studies and our studies may result from the following factors: different cell types, different dosages, and the interactions between them. The interesting issue here is why the low-dose proteasome inhibitor MG132 relating to endothelial cells downregulate the eNOS protein expression in EPCs. One possible explanation would be that the dosages used in our studies exerted cytotoxicity on EPCs. Similarly to endothelial cells, high doses of MG132 induced endothelial cells to apoptosis, diminished expression of eNOS and NO production (16). Probably the dosages used in our studies may not be low and nontoxic doses to EPCs.

Moreover, the ubiquitin-proteasome pathway plays an important role in the biology of mammalian stem and progenitor cells (40). Several studies documented that the ubiquitin-proteasome pathway was essentially involved in the regulation of survival, proliferation, differentiation, and lineage commitment of human CD34-positive hematopoietic progenitor cells $(41,42)$. It has previously been shown that proteasome inhibitors exert antiangiogenic activity in in vitro and in vivo models of angiogenesis, by reducing the 
expression of VEGF receptor-1, VEGF secretion by endothelial cells in a dose-dependent manner $(43,44)$. VEGF is one of the major angiogenic growth factors, which may induce migration, proliferation and tube formation in EPCs $(45,46)$. Since sufficient amounts of exogenous VEGF were present in our medium during EPCs culture, the above mechanism may not be responsible for our findings. Though unlikely, we cannot exclude the possibility that the proteasome inhibitors may decrease VEGF activity via other mechanism, since the proteasome is involved in many cellular processes.

In conclusion, our present study showed that proteasome inhibitor MG132, at concentrations known for partial proteasome inhibition in endothelial cells $(15,16)$, directly suppresses number and function of endothelial progenitor cells, which appears to disturb the eNOS/NO pathway. The detrimental effects of MG132 on EPCs may affect reendothelialization after stent implantation, and may lead to endothelial dysfunction. Pioneering work in this area is warranted and should assess the optimum dosage and side effect in local drug therapy.

\section{Acknowledgements}

This work is supported by the grants from Natural Science Foundation of Zhejiang province (No. Y208374) and Health Bureau of Zhejiang Province (No. 2005A019).

\section{References}

1. Asahara T, Murohara T, Sullivan A, Silver M, van der Zee R, Li T, Witzenbichler B, Schatteman G and Isner JM: Isolation of putative endothelial progenitor cells for angiogenesis. Science 275: 964-967, 1997

2. Walter DH, Rittig K, Bahlmann FH, et al: Statin therapy accelerate reendothelialization: a novel effect involving mobilization and incorporation of bone marrow-derived endothelial progenitor cells. Circulation 105: 3017-3024, 2002.

3. Assmus B, Schachinger V, Teupe C, et al: Transplantation of progenitor cells and regeneration enhancement in acute myocardial infarction (TOPCARE-AMI). Circulation 106: 3009-3017, 2002.

4. Hill JM, Zalos G, Halcox JP, Schenke WH, Waclawiw MA, Quyyumi AA and Finkel T: Circulating endothelial progenitor cells, vascular function, and cardiovascular risk. N Engl J Med 348: 593-600, 2003.

5. Vasa M, Fichtlscherer S, Aicher A, Adler K, Urbich C, Martin H, Zeiher AM and Dimmeler S: Number and migratory activity of circulating endothelial progenitor cells inversely correlate with risk factors for coronary artery disease. Circ Res 89: E1-E7, 2001.

6. Schmidt-Lucke C, Rossig L, Fichtlscherer S, et al: Reduced number of circulating endothelial progenitor cells predicts future cardiovascular events: proof of concept for the clinical importance of endogenous vascular repair. Circulation 111: 2981-2987, 2005.

7. Aicher A, Heeschen C, Mildner-Rihm C, Urbich C, Ihling C, Technau-Ihling K, Zeiher AM and Dimmeler S: Essential role of endothelial nitric oxide synthase for mobilization of stem and progenitor cells. Nat Med 9: 1370-1376, 2003.

8. Guthrie SM, Curtis LM, Mames RN, Simon GG, Grant MB and Scott EW: The nitric oxide pathway modulates hemangioblast activity of adult hematopoietic stem cells. Blood 105: 1916-1922, 2005.

9. Hiasa K, Ishibashi M, Ohtani K, et al: Gene transfer of stromal cell-derived factor- 1 alpha enhances ischemic vasculogenesis and angiogenesis via vascular endothelial growth factor/ endothelial nitric oxide synthase-related pathway: next-generation chemokine therapy for therapeutic neovascularization. Circulation 109: 2454-2461, 2004.
10. Vasa M, Fichtlscherer S, Adler K, Aicher A, Martin H, Zeiher AM and Dimmeler S: Increase in circulating endothelial progenitor cells by statin therapy in patients with stable coronary artery disease. Circulation 103: 2885-2890, 2001.

11. Lee DH and Goldberg AL: Proteasome inhibitors: Valuable new tools for cell biologists. Trends Cell Biol 8: 397-403, 1998.

12. Voorhees PM and Orlowski RZ: The proteasome and proteasome inhibitors in cancer therapy. Annu Rev Pharmacol Toxicol 46: 189-213, 2006.

13. Adams J: The proteasome A suitable antineoplastic target. Nat Rev Cancer 4: 349-360, 2004.

14. Meiners S, Ludwig A, Stangl V and Stangl K: Proteasome inhibitors: poisons and remedies. Med Res Rev 28: 309-327, 2008.

15. Stangl V, Lorenz M, Meiners S, Ludwig A, Bartsch C, Moobed M, Vietzke A, Kinkel HT, Baumann G and Stangl K: Long-term up-regulation of eNOS and improvement of endothelial function by inhibition of the ubiquitin-proteasome pathway. FASEB J 18: 272-279, 2004

16. Meiners S, Ludwig A, Lorenz M, Dreger H, Baumann G, Stangl V and Stangl K: Nontoxic proteasome inhibition activates a protective antioxidant defense response in endothelial cells. Free Radic Biol Med 40: 2232-2241, 2006.

17. Drexler HC, Risau W and Konerding MA: Inhibition of proteasome function induces programmed cell death in proliferating endothelial cells. FASEB J 14: 65-77, 2000.

18. Wojcik C: Proteasomes in apoptosis: Villains or guardians? Cell Mol Life Sci 56: 908-917, 1999.

19. Chen JZ, Zhu JH, Wang XX, Zhu JH, Xie XD, Sun J, Shang YP, Guo XG, Dai HM and Hu SJ: Effects of homocysteine on number and activity of endothelial progenitor cells from peripheral blood. J Mol Cell Cardiol 36: 233-239, 2004.

20. Assmus B, Urbich C, Aicher A, et al: HMG-CoA reductase inhibitors reduce senescence and increase proliferation of endothelial progenitor cells via regulation of cell cycle regulatory genes. Circ Res 92: 1049-1055, 2003.

21. Zhu JH, Chen JZ, Wang XX, Xie XD, Sun J and Zhang FR: Homocysteine accelerates senescence and reduces proliferation of endothelial progenitor cells. J Mol Cell Cardiol 40: 648-652, 2006.

22. Liu X, Fan XL, Zhao Y, Luo GR, Li XP, Li R and Le WD: Estrogen provides neuroprotection against activated microgliainduced dopaminergic neuronal injury through both estrogen receptor-alpha and estrogen receptor-beta in microglia. J Neurosci Res 81: 653-665, 2005.

23. Herrmann J, Saguner AM, Versari D, Peterson TE, Chade A, Olson M, Lerman LO and Lerman A: Chronic proteasome inhibition contributes to coronary atherosclerosis. Circ Res 101: 865-874, 2007.

24. Kostin S, Pool L, Elsässer A, et al: Myocytes die by multiple mechanisms in failing human hearts. Circ Res 92: 715-724, 2003.

25. Pye J, Ardeshirpour F, McCain A, et al: Proteasome inhibition ablates activation of NF-kappa B in myocardial reperfusion and reduces reperfusion injury. Am J Physiol Heart Circ Physiol 284: H919-H926, 2003.

26. Meiners S, Laule M, Rother W, Guenther C, Prauka I, Muschick P, Baumann G, Kloetzel PM and Stangl K: Ubiquitin-proteasome pathway as a new target for the prevention of restenosis. Circulation 105: 483-489, 2002.

27. Depre C, Wang Q, Yan L, et al: Activation of the cardiac proteasome during pressure overload promotes ventricular hypertrophy. Circulation 114: 1821-1828, 2006.

28. Kisselev AF and Goldberg AL: Proteasome inhibitors: From research tools to drug candidates. Chem Biol 8: 739-758, 2001.

29. Veschini L, Belloni D, Foglieni C, Cangi MG, Ferrarini M, Caligaris-Cappio F and Ferrero E: Hypoxia-inducible transcription factor- 1 alpha determines sensitivity of endothelial cells to the proteasome inhibitor bortezomib. Blood 109: 2565-2570, 2007

30. Bross PF, Kane R, Farrell AT, et al: Approval summary for bortezomib for injection in the treatment of multiple myeloma. Clin Cancer Res 10: 3954-3964, 2004.

31. Chade AR, Herrmann J, Zhu X, Krier JD, Lerman A and Lerman LO: Effects of proteasome inhibition on the kidney in experimental hypercholesterolemia. J Am Soc Nephrol 16: 1005-1012, 2005.

32. Takaoka M, Itoh M, Kohyama S, Shibata A, Ohkita M and Matsumura Y: Proteasome inhibition attenuates renal endothelin-1 production and the development of ischemic acute renal failure in rats. J Cardiovasc Pharmacol 36: S225-S227, 2000. 
33. Okamoto $H$, Takaoka $M$, Ohkita $M$, Itoh $M$, Nishioka $M$ and Matsumura YA: proteasome inhibitor lessens the increased aortic endothelin-1 content in deoxycorticosterone acetate-salt hypertensive rats. Eur J Pharmacol 350: R11-R12, 1998.

34. Maki CG, Huibregtse JM and Howley PM: In vivo ubiquitination and proteasome-mediated degradation of p53. Cancer Res 56 : 2649-2654, 1996.

35. Salghetti SE, Kim SY and Tansey WP: Destruction of Myc by ubiquitinmediated proteolysis: cancer-associated and transforming mutations stabilize Myc. EMBO J 18: 717-726, 1999.

36. Yang Y, Fang S, Jensen JP, Weissman AM and Ashwell JD: Ubiquitin protein ligase activity of IAPs and their degradation in proteasomes in response to apoptotic stimuli. Science 288 874-877, 2000

37. Ganten TM, Koschny R, Haas TL, Sykora J, Li-Weber M, Herzer K and Walczak H: Proteasome inhibition sensitizes hepatocellular carcinoma cells, but not human hepatocytes, to TRAIL. Hepatology 42: 588-597, 2005.

38. Govers R, Bree P and Rablink TJ: Involvement of the proteasome in activation of endothelial nitric oxide synthase. Life Sci 73: 2225-2236, 2003.

39. Wei Q and Xia Y: Proteasome inhibition down-regulates endothelial nitric-oxide synthase phosphorylation and function. J Biol Chem 281: 21652-21659, 2006.

40. Naujokat $\mathrm{C}$ and Saric T: Concise review: Role and function of the ubiquitin-proteasome system in mammalian stem and progenitor cells. Stem Cells 25: 2408-2418, 2007.
41. Naujokat C, Sezer O, Zinke H, Leclere A, Hauptmann S and Possinger K: Proteasome inhibitors induce caspase-dependent apoptosis and accumulation of p21WAF1/Cip 1 in human immature leukemic cells. Eur J Haematol 65: 221-236, 2000.

42. Zavrski I, Naujokat C, Niemöller K, Jakob C, Heider U, Langelotz C, Fleissner C, Eucker J, Possinger K and Sezer O: Proteasome inhibitors induce growth inhibition and apoptosis in myeloma cell lines and in human bone marrow myeloma cells irrespective of chromosome 13 deletion. J Cancer Res Clin Oncol 129: 383-391, 2003.

43. Oikawa T, Sasaki T, Nakamura M, Shimanmura M, Tanahashi N, Omura S and Tanaka $\mathrm{K}$ : The proteasome is involved in angiogenesis. Biochem Biophys Res Commun 246: 243-248, 1998.

44. Roccaro AM, Hideshima T, Raje N, et al: Bortezomib mediates antiangiogenesis in multiple myeloma via direct and indirect effects on endothelial cells. Cancer Res 66: 184-191, 2006.

45. Asahara T, Takahashi T, Masuda H, Kalka C, Chen D, Iwaguro H, Inai $\mathrm{Y}$, Silver $\mathrm{M}$ and Isner JM: VEGF contributes to postnatal neovascularization by mobilizing bone marrow-derived endothelial progenitor cells. EMBO J 18: 3964-3972, 1999.

46. Wijelath ES, Rahman S, Murray J, Patel Y, Savidge G and Sobel M: Fibronectin promotes VEGF-induced CD34 cell differentiation into endothelial cells. J Vasc Surg 39: 655-660, 2004. 